\title{
Chinese Herbal Medicine for Severe Acute Respiratory Syndrome: A Systematic Review and Meta-Analysis
}

\author{
JIANPING LIU, M.D., Ph.D., ${ }^{1}$ ERIC MANHEIMER, M.S., ${ }^{2}$ YI SHI, M.D., ${ }^{3}$ \\ and CHRISTIAN GLUUD, M.D., Dr.Med.Sci. ${ }^{4}$
}

\begin{abstract}
Objectives: To review randomized controlled trials (RCTs) evaluating the effects of Chinese herbal medicine for treating severe acute respiratory syndrome (SARS) systematically.

Design: Electronic and manual searches identified RCTs comparing Chinese medicine integrated to conventional medicine versus conventional medicine alone. Methodological quality of trials was assessed by generation of allocation sequence, allocation concealment, blinding, and intention-to-treat.

Results: Eight RCTs (488 patients with SARS) were included. The methodological quality was generally low. The combined therapy showed significant reduction of mortality (relative risk 0.32 [95\% confidence interval $\{\mathrm{CI}\} 0.12$ to 0.91$]$ ), shortened duration of fever, symptom relief, reductions in chest radiograph abnormalities, and reductions in secondary fungal infections among patients receiving glucocorticoids. There were no significant effects on quality of life or glucocorticoid dosage.

Conclusion: Chinese herbal medicine combined with conventional medicine may have beneficial effects in patients with SARS. The evidence is insufficient because of the low methodological quality of the included trials.
\end{abstract}

\section{INTRODUCTION}

$\mathbf{S}_{\mathrm{N}}^{\mathrm{c}}$ evere acute respiratory syndrome (SARS) emerged in November 2002 as a highly infectious disease associated with substantial morbidity and mortality. SARS caused 916 deaths before temporarily disappearing in the summer of 2003. Three new cases of laboratory-confirmed infection emerged in January 2004 (www.who.int/csr/don/2004 01_31/en/). The World Health Organization (WHO) estimates that the case fatality rate varies depending on age group: the rate is less than $1 \%$ in persons aged 24 years or younger; $6 \%$ in persons aged 25 to 44 years; $15 \%$ in persons aged 45 to 64 years; and greater than $50 \%$ in persons aged 65 years and older (Donnelly et al., 2003; World Health Organization, 2003b).
Caused by a novel coronavirus, SARS is predominantly spread by infected water droplets across short distance among close contacts, although indirect transmission is also possible (Mora et al., 2003; Peiris et al., 2003; Rota et al., 2003). Medical personnel are among those commonly infected because of their close contact with symptomatic and highly infectious cases. The advent of SARS poses an immense challenge to the affected health care communities and economies.

There is no consensus on the preferred treatment for SARS. Treatments used to date have been based on pathophysiologic rationale or on the experience obtained from case series collected during the early stages of the epidemic. Glucocorticoids and ribavirin have been administered most frequently during the early stages of the epidemic, yet in-

\footnotetext{
${ }^{1}$ International Health Research Group, Liverpool School of Tropical Medicine, Liverpool, United Kingdom.

${ }^{2}$ Center for Integrative Medicine, University of Maryland School of Medicine, Kernan Hospital Mansion, Baltimore, MD.

${ }^{3}$ The Institute of Traditional Chinese Medicine Literature, Shanghai University of Traditional Chinese Medicine, Shanghai, China.

${ }^{4}$ Copenhagen Trial Unit, Centre for Clinical Intervention Research, Copenhagen University Hospital, Copenhagen, Denmark.
} 
sufficient evidence exists for their efficacy (Wenzel and Edmond, 2003; Wong and Hui, 2003). Antibiotics, other antiviral drugs (e.g., interferon, neuraminidase inhibitor), and other supportive treatments have also been widely used. Based on the anecdotal experience of traditional Chinese doctors in Guangzhou, different herbal medicines were combined with the conventional drugs, and this combined approach was claimed to be more effective than conventional drugs alone (Anonymous, 2003; Lin et al., 2003; Ma, 2003).

In April 2003, China's State Administration of Traditional Chinese Medicine (TCM; 2003) and the Chinese Ministry of Health coannounced an advocacy for the use of herbal medicines in the treatment of SARS. Eight specific herbal formulations were recommended after a screening of more than 30 herbal medicines used for SARS patients (Duan, 2003; Wang, 2003). The eight formulae are Banlangen Keli (Baphicacanthi granule), Jinlian Qingre granule, Xinxue granule, and Dengzhan Xixin, Fufang Kushen, Qingkailing, Xiangdan, and Yuxingcao injections. More than half of patients with SARS in Beijing received treatment with herbal medicine plus conventional drugs, according to the State Administration of TCM (Duan, 2003).

Clinical studies, ranging from case reports and case series to controlled observational studies and randomized clinical trials, have been conducted and reported. Clearly, there is a critical need to investigate systematically the beneficial and harmful effects of TCM approaches for treating SARS.

\section{MATERIALS AND METHODS}

\section{Search strategy}

To identify relevant studies, we searched the following databases from November 2002 through December 2003: The Cochrane Library, PubMed, Chinese Biomedical Database, Chinese Journals Full-text Database, Chinese Scientific Journal Database, trials database of the Cochrane Collaboration Complementary Medicine Field, and the Allied and Complementary Database. We used the search terms "atypical pneumonia," "severe acute respiratory syndrome," "SARS," "Traditional Chinese Medicine," "herbal medicine," and "integrative medicine." Various combinations of the terms were used, depending on the database searched. Relevant Chinese newspapers and Internet websites such as WHO, U.S. Centers for Disease Control (CDC), and China CDC were also screened, and reference lists of identified papers and review articles were checked.

\section{Inclusion criteria}

We included randomized clinical trials comparing herbal medicines plus conventional drugs versus placebo/no intervention plus conventional drugs in patients with SARS on clinical outcomes. In an exploratory analysis, we included nonrandomized controlled studies on medicinal herbs com- pared to placebo/no intervention to investigate the potential impact of study design on the primary outcome measure (death). Eligible studies had to include patients meeting the WHO criteria for a confirmed or suspected case of SARS (www.who.int/csr/sars/) (during the earliest stage of the SARS epidemic, patients with SARS were diagnosed as "atypical pneumonia" in China, and the diagnostic criteria of "atypical pneumonia" conformed to the WHO criteria). Published and unpublished studies were included irrespective of languages or masking. When more than one publication described a single study, we extracted data from the one providing the most detailed information.

\section{Validity assessment}

The methodological quality of trials was assessed using the generation of the allocation sequence, the allocation concealment, double blinding, and withdrawals/dropouts (Clarke and Oxman, 2003; Kjaergard et al., 2001; Moher et al., 1998; Schulz et al., 1995).

\section{Data abstraction}

Two reviewers (J.L. and Y.S.) extracted the data independently, and any disagreement was resolved by discussion. The following study characteristics were tabulated from trials: design, participants and diagnosis, intervention regimen, and clinical outcomes. Outcome measures to be extracted included death, number of complications, symptoms, quality of life, use of glucocorticoids, findings on chest radiograph, biochemistry, and adverse events.

\section{Data synthesis}

We used the statistical package (RevMan 4.2.3) provided by The Cochrane Collaboration for data analyses. Dichotomous data were presented as relative risk (RR) and continuous outcomes as weighted mean difference (WMD), both with $95 \%$ confidence interval $(\mathrm{CI})$. We assessed data by both random effects and fixed effect analyses, but only reported the fixed effect analysis if the overall conclusion was the same with both analyses. We assessed heterogeneity by the $\mathrm{I}^{2}$ statistic and used $p<0.10$ as a significance limit for heterogeneity (Higgins et al., 2003). An exploratory analysis was performed using data from the nonrandomized studies. Publication bias was examined by funnel plot, that is, a graphical display of sample size plotted against effect size, if data allowed (Egger et al., 1997).

\section{RESULTS}

\section{Description of studies}

We identified 193 records on SARS from electronic and manual searches (Fig. 1). By reading titles and abstracts, we 


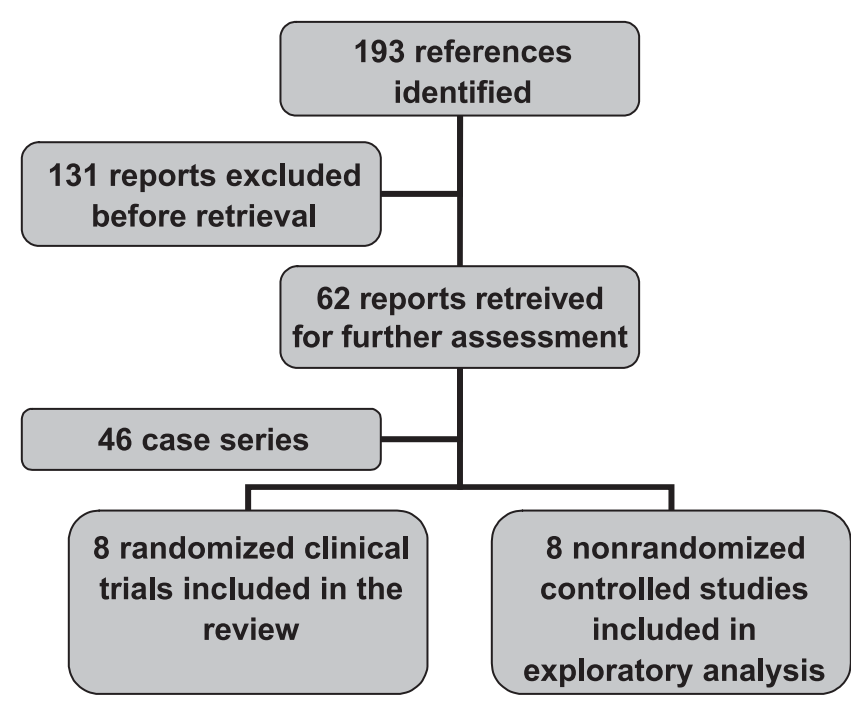

FIG. 1. Flow chart of study selection.

excluded 131 citations that were clearly duplicates, review articles, or nonclinical studies. A total of 62 articles published in Chinese or English were retrieved for further assessment. Of these, 46 articles were excluded because they were noncontrolled clinical studies including case reports and case series. In total, 8 randomized clinical trials (Bian et al., 2003; Kang et al., 2003; Lei et al., 2003; Li et al., 2003d; Wang et al., 2003; Zhang, 2003; Zhang et al., 2003; Zhao et al., 2003) were identified and they reported to allocate SARS patients randomly $(n=488)$ to herbal medicine plus conventional drugs or to conventional drugs alone. The characteristics of 8 randomized trials are summarized in Table 1. Two of the trials had been published twice (Wang et al., 2003; Zhang et al., 2003). We also identified 8 nonrandomized controlled studies (Dai et al., 2003; He et al., 2003; Jiao et al., 2003; Li et al., 2003a, 2003b; Sun et al., 2003; Zhang et al., 2003) that compared herbal medicine plus conventional drugs to conventional drugs alone for SARS patients $(n=605)$ (Table 2). One of the studies had been published four times in different journals ( $\mathrm{Li}$ et al., 2003c).

All eight randomized trials were small, ranging from 40 to 91 participants per trial. All trials included Chinese patients with SARS. The trial reports did not state whether the diagnosis was confirmed by laboratory testing. The types, constituents, dosages, and methods of administration of the herbal medicines used for treating SARS varied, and most of the trials used several different herbal medicines during the disease course (Table 1).

\section{Methodological quality of included studies}

Of the eight trials, only two described the method to generate the allocation sequence (both used random number tables) (Bian et al., 2003; Wang et al., 2003). No trial pro- vided information on allocation concealment, double blinding, withdrawals/dropouts, intention-to-treat, or prior sample size estimation. Accordingly, the included trials had generally low methodological quality (Bian et al., 2003; Kang et al., 2003; Lei et al., 2003; Li et al., 2003e; Wang et al., 2003; Zhang et al., 2003a, 2003b; Zhao et al., 2003). Four of eight trials failed to provide baseline data for the comparability between groups (Lei et al., 2003; Zhang et al., 2003a, 2003b; Zhao et al., 2003).

The eight nonrandomized studies that were compared in an exploratory analysis also had poor quality in terms of design, methodology, and reporting (Table 3) (Dai et al., 2003; He et al., 2003; Jiao et al., 2003; Li et al., 2003a, 2003b, 2003c; Sun et al., 2003; Zhang et al., 2003). Outcomes are summarized in Tables 3 and 4.

\section{Mortality}

A meta-analysis of five randomized trials (Li et al., 2003e; Wang et al., 2003; Zhang et al., 2003a, 2003b; Zhao et al., 2003) showed that a statistically significant difference in mortality existed between the combined therapy and the conventional drugs in patients with SARS (RR 0.32 [95\% CI 0.12 to 0.91$] ; n=294)$. The $\mathrm{I}^{2}$ statistic indicated no significant heterogeneity among the trials. Three trials did not provide data on death. Pooling data from six non-randomized controlled studies (Dai et al., 2003; He et al., 2003b, 2003c; Sun et al., 2003; Zhang et al., 2003) showed a statistically significant beneficial effect of combined therapy compared to conventional drugs ( 0.27 [0.12 to 0.61$] ; n=486)$ with no significant heterogeneity.

\section{Fever and symptom}

Three randomized trials (Lei et al., 2003; Li et al., 2003e; Zhao et al., 2003) showed a significant benefit of the combined therapy versus conventional drugs in shortening the duration of fever. A pooled result of two trials (Lei et al., 2003; Li et al., 2003e) showed significant benefit from the combined therapy versus conventional drugs in shortening the time to symptom relief. One trial (Bian et al., 2003) evaluated quality of life in 40 patients with SARS at the convalescent stage, and the scales used included limitation in activity, difficulty in breathing, and emotion. The results showed no significant difference in the overall scores of quality of life comparing combined therapy versus conventional drugs.

\section{Chest radiograph abnormalities}

Seven trials reported outcome of lung radiograph (Kang et al., 2003; Lei et al., 2003; Li et al., 2003e; Wang et al., 2003; Zhang et al., 2003a, 2003b; Zhao et al., 2003). A metaanalysis showed significant benefit of the combined therapy versus conventional drugs in shortening the average time to resolution of the lung inflammation from three trials (Lei et 
LIU ET AL.

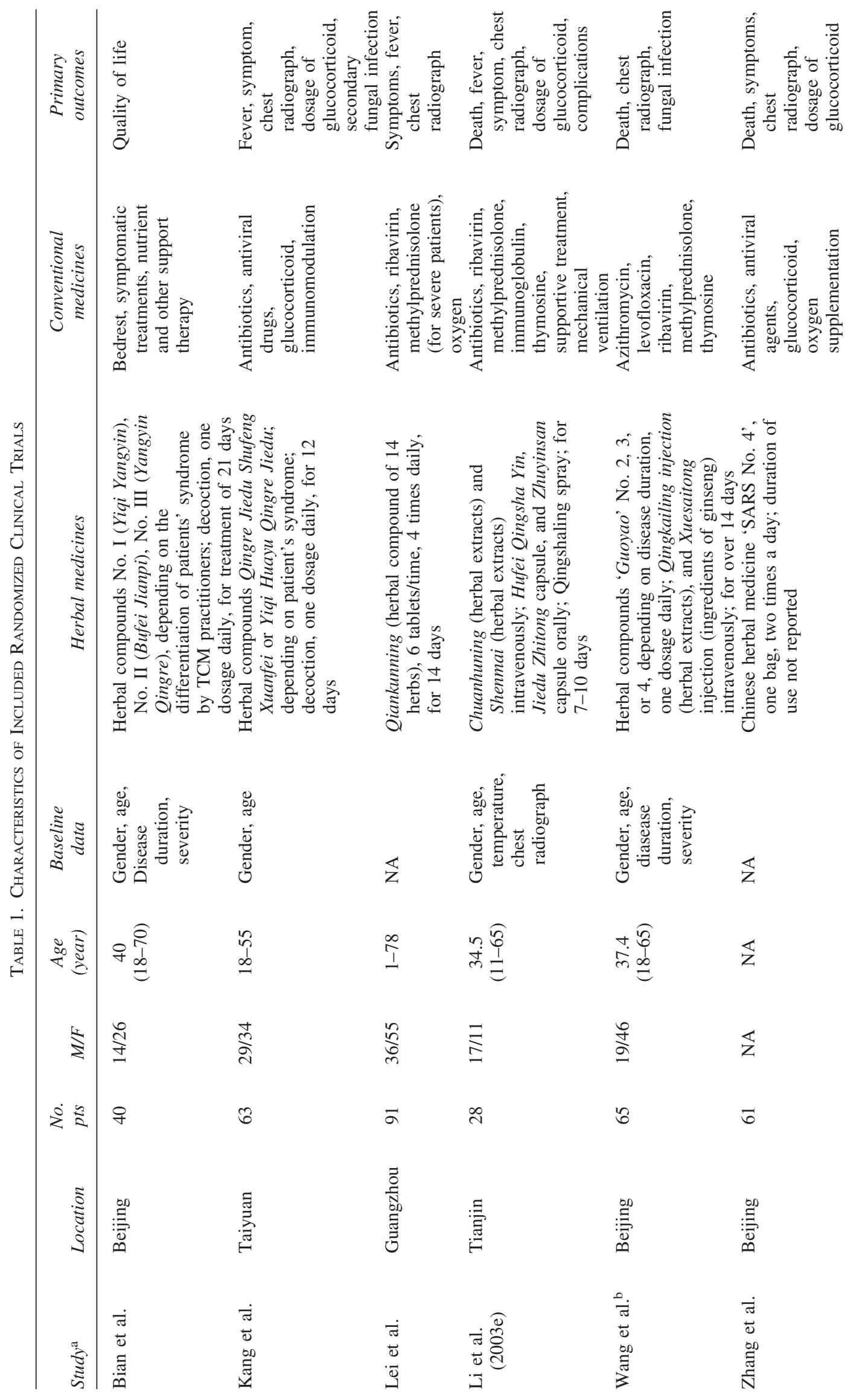



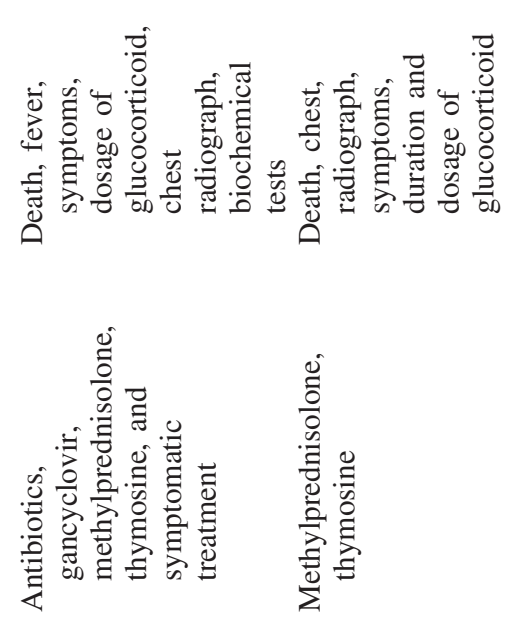

i

iो

표

乙

ㅎํㅇํำ

:

is

氖导

害

ㅎํㅇ. 홍

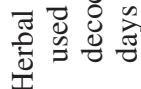

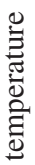

$\widehat{n}$
$=$
$\infty$
$=$

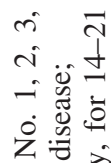

之:

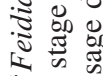

릉ㅇㅁ

氙氖

遅它.

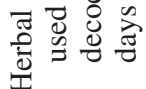

.

ฏे

8

:

$\overleftrightarrow{z}$

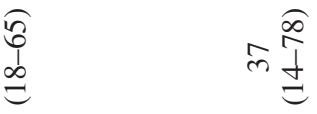

商

乏

$\frac{\sqrt{n}}{\text { 里 }}$

ส

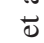

艺

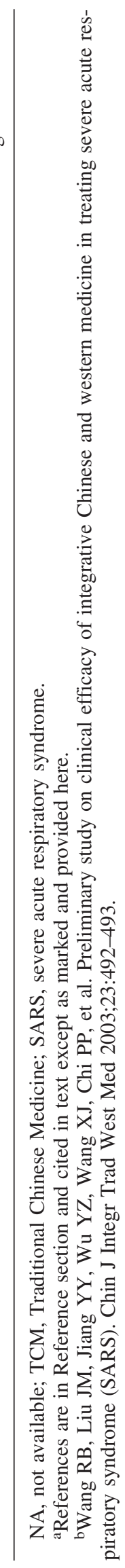




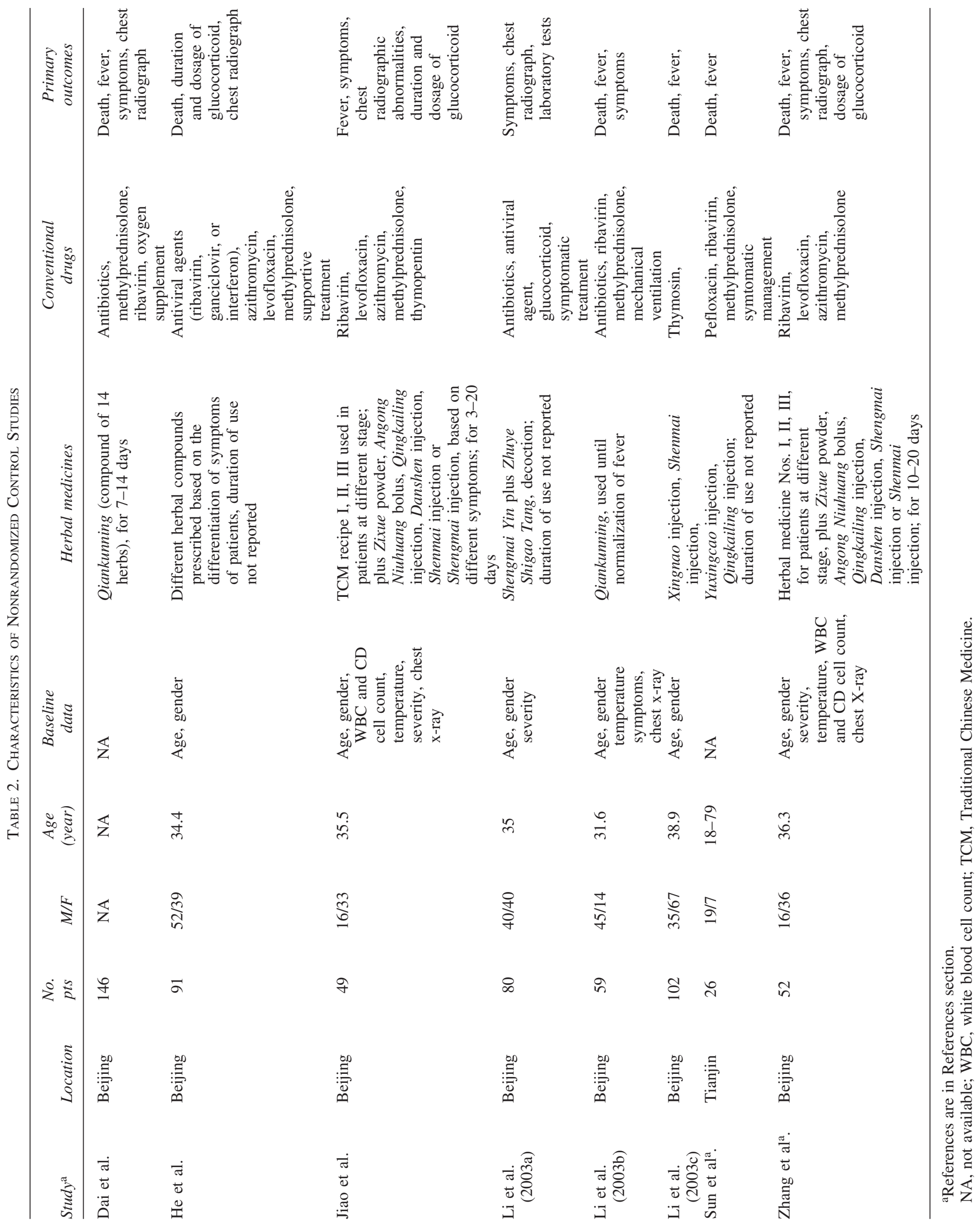


Table 3. Comparison of Randomized and Nonrandomized Studies on Mortality

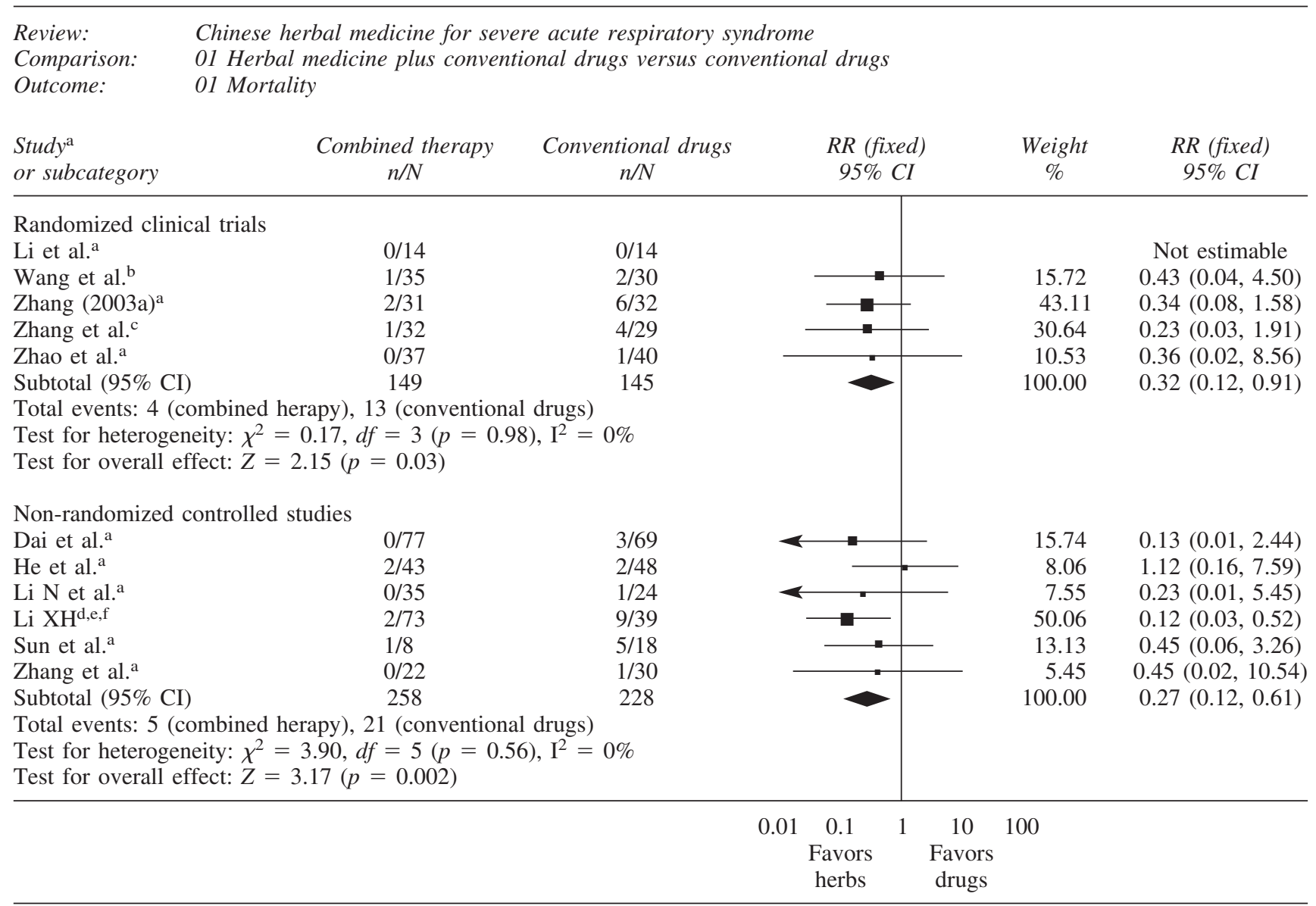

$\mathrm{RR}$, relative risk; CI, confidence interval.

aReference is in References section.

${ }^{b}$ Wang RB, Liu JM, Jiang YY, Wu YZ, Wang XJ, Chi PP, et al. Preliminary study on clinical efficacy of integrative Chinese and western medicine in treating severe acute respiratory syndrome (SARS). Chin J Integr Trad West Med 2003;23:492-493.

'Zhang XM, Feng GL, Ma YM. Clinical recording of infectious atypical pneumonia (SARS) treated by integrated Chinese and western medicines. China's Naturopathy. 2003;11:4-6.

${ }^{\mathrm{d}} \mathrm{Li} \mathrm{XH}, \mathrm{Hu} \mathrm{JH}$, Zhang K, Ye J, Gou CY, Li Y, et al. Clinical effective observation on integrated traditional Chinese and western medicine in treatment of 51 severe SARS patients. Chin J Integr Trad West Med Intens Crit Care 2003d;10:259-261.

${ }^{\mathrm{E}} \mathrm{Li} \mathrm{XH}$, Zhang K, Hu JH, Guo XH, Hu ZJ, Yang Y, et al. Clinical observation on effects of treatment of severe acute respiratory syndrome (SARS) by integrative Chinese and western medicine. Chin J Integr Trad West Med 2003e;23:489-491.

fLi XH, Zhang K, Hu JH, Guo XH, Hu ZJ, Yang Y, et al. Clinical evaluation of integrative Chinese and western medicine in treating SARS. Chin J Integr Med 2003f;9:181-184.

al., 2003; Li et al., 2003e; Zhang et al., 2003a) and reducing the number of lung radiographic abnormalities from two trials (Kang et al., 2003; Zhang et al., 2003b). The remaining trials did not provide adequate lung radiographic data for analyses because of incomplete reporting.

\section{Glucocorticoids and secondary fungal infections}

Five trials (Kang et al., 2003; Li et al., 2003e; Zhang et al., 2003a, 2003b; Zhao et al., 2003) reported the dosages of methylprednisolone used in both intervention groups. The combined result of three trials (Li et al., 2003e; Zhang et al., 2003a; Zhao et al., 2003) did not show significant glucocorticoid-reducing effect of the combined therapy compared to conventional drugs using random effects model due to significant heterogeneity $\left(\mathrm{I}^{2}=99.2 \%\right.$; $p<0.00001$ ). Two trials (Kang et al., 2003; Zhang et al., $2003 \mathrm{~b}$ ) reported average daily dosage of methylprednisolone, and there was no significant difference between the treatment groups. A pooled result of two trials (Kang et al., 2003; Wang et al., 2003) showed significant benefit of the combined therapy versus conventional drugs on reducing the number of secondary fungal infections in patients with SARS treated with glucocorticoid (RR 0.35 [0.14 to 0.90$] ; p=0.03$ ).

No trial provided information on adverse events. 
Table 4. Summary for Outcome Variables of Randomized Clinical Trials

\begin{tabular}{|c|c|c|c|c|c|}
\hline & $\begin{array}{l}\text { No. of trials } \\
{\text { (references })^{\mathrm{a}}}^{\text {refere }}\end{array}$ & $\begin{array}{c}\text { Herbal } \\
\text { medicines } \\
\text { (events/pts) }\end{array}$ & $\begin{array}{c}\text { Conventional } \\
\text { drugs } \\
\text { (events/pts) }\end{array}$ & $\begin{array}{c}\text { Relative risk } \\
(95 \% \text { confidence interval) }\end{array}$ & $\begin{array}{c}\mathrm{p} \\
\text { value }\end{array}$ \\
\hline Mortality & $\begin{array}{l}5 \text { (Li et al., 2003e; } \\
\text { Wang et al., 2003; } \\
\text { Zhang et al., 2003a, } \\
\text { 2003b; Zhao et al., } \\
\text { 2003) }\end{array}$ & $4 / 149$ & $13 / 145$ & $0.32(0.12$ to 0.91$)$ & 0.03 \\
\hline $\begin{array}{l}\text { Incidence of secondary } \\
\text { fungal infection }\end{array}$ & $\begin{array}{l}2 \text { (Kang et al., 2003; } \\
\text { Wang et al., 2003) }\end{array}$ & $6 / 78$ & $9 / 50$ & $0.35(0.14$ to 0.90$)$ & 0.03 \\
\hline \multirow[t]{2}{*}{$\begin{array}{l}\text { Abnormal chest } \\
\text { radiograph }\end{array}$} & $\begin{array}{l}2 \text { (Kang et al., 2003; } \\
\text { Zhang et al., 2003) }\end{array}$ & $10 / 74$ & $24 / 52$ & $0.29(0.15$ to 0.56$)$ & 0.0002 \\
\hline & & No. of pts. & No. of pts. & $\begin{array}{l}\text { Weighted mean difference } \\
\text { (95\% confidence interval) }\end{array}$ & \\
\hline $\begin{array}{l}\text { Duration to fever } \\
\text { clearance (days) }\end{array}$ & $\begin{array}{l}3 \text { (Lei et al., 2003; } \\
\text { Li et al., 2003; } \\
\text { Zhang et al., 2003) }\end{array}$ & 95 & 87 & $-0.83(-1.30$ to -0.35$)$ & 0.0006 \\
\hline $\begin{array}{l}\text { Duration to symptom } \\
\text { relief (days) }\end{array}$ & $\begin{array}{l}2 \text { (Lei et al., 2003; } \\
\text { Li et al., 2003e) }\end{array}$ & 64 & 55 & $-1.23(-2.09$ to -0.37$)$ & 0.005 \\
\hline $\begin{array}{c}\text { Duration to resolution } \\
\text { of chest radiograph }\end{array}$ & $\begin{array}{l}3 \text { (Lei et al., 2003; } \\
\text { Li et al., 2003e; } \\
\text { Zhang et al., 2003a) }\end{array}$ & 95 & 80 & $-2.27(-3.16$ to -1.39$)$ & $<0.00001$ \\
\hline $\begin{array}{l}\text { Total dosage of } \\
\text { glucocorticoids (mg) }\end{array}$ & $\begin{array}{l}3 \text { (Li et al., 2003e; } \\
\text { Zhang et al., 2003; } \\
\text { Zhao et al., 2003) }\end{array}$ & 60 & 59 & $-770.45(-1798.47 \text { to } 257.58)^{\mathrm{b}}$ & 0.14 \\
\hline $\begin{array}{l}\text { Daily dosage of } \\
\text { glucocorticoids (mg) }\end{array}$ & $\begin{array}{l}2 \text { (Kang et al., 2003; } \\
\text { Zhang et al., 2003) }\end{array}$ & 74 & 52 & $-54.13(-120.63$ to 12.38$)$ & 0.11 \\
\hline Quality of life (score) & 1 (Bian et al., 2003) & 20 & 20 & $-2.20(-4.93$ to 0.53$)$ & 0.11 \\
\hline
\end{tabular}

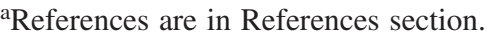

${ }^{b}$ Random effects model.

\section{DISCUSSION}

Based on this review and meta-analyses, herbal medicines given in combination with conventional drugs seem superior to conventional drugs alone for patients with SARS. Herbal medicines show benefit on mortality and on shortening the duration to temperature normalization, symptom relief, and resolution of chest radiograph abnormalities, as well as on reducing the incidence of fungal infections. We cannot draw conclusions about the safety of using herbal medicine because no trial provided information on adverse events.

Before accepting the findings of this review to form a basis for clinical practice, one must consider the following weaknesses. First, the randomized trials in this review had several methodological flaws in terms of generation of the allocation sequence, allocation concealment, and blinding. They provided limited descriptions of study design, and most trials stated only that patients were randomly assigned; thus the information does not allow a judgment of whether or not it was conducted properly. We therefore caution that the differences between the combined treatment and con- ventional drugs may be associated with the methodologically less rigorous trials (Clarke and Oxman, 2003; Kjaergard et al., 2001; Moher et al., 1998; Schulz et al., 1995). The number of trials identified limits us to perform meaningful subgroup or sensitivity analyses to illuminate robustness of the results in the review.

Second, epidemiologic studies on SARS have shown that age of the patients is strongly associated with mortality (Donnelly et al., 2003; World Health Organization, 2003b). None of the randomized trials used age as a stratification variable during randomization in spite of the fact that all trials were small. Furthermore a number of the trials and nonrandomized studies lack reporting of baseline data of the groups, including age. Therefore, unbalanced distribution of the important prognostic variable age between the intervention groups may partly explain the significant findings of the present systematic review.

Third, Vickers and colleagues (1998) found that some countries, including China, publish unusually high proportions of positive results, for which publication bias is a possible explanation. All identified studies for this systematic review was originating from China. The number of trials 
identified in this review is too small for us to explore quantitatively the possibility of publication bias. But we note that some studies, both randomized and nonrandomized, have been published several times with the same data set.

Fourth, the use of herbal medicines varied both among the trials as well as during the conduct of the individual trials. This adds to the complexity of interpreting the present findings. TCM drug treatment, however, consists typically in complex prescriptions of combination of several components and uses such flexible administration of interventions so that they can be adjusted to reflect changes in the patient's condition or syndrome (Chan, 1995). The combination is based on the Chinese diagnosis that follows a completely different rationale than many Western herbal treatments.

Given the low methodological quality of the randomized trials, the risks of unbalanced distribution of prognostic factors and the publication bias, the multitude of different herbs used, and the small size of trials, we find it premature to conclude that the combination of herbal medicines and conventional drugs has been proven superior to conventional drugs alone for SARS patients. In spite of the fact that our exploratory analysis supported the findings from the randomized trials, nonrandomized studies may overestimate and underestimate intervention effects (Kunz et al., 2003). Hence, using nonrandomized studies in support of potentially biased clinical trials may be unreliable.

The use of glucocorticoids for patients with SARS remains controversial ( $\mathrm{Li}$ et al., 2003d; Oba, 2003; Wang, 2003), and to date there is no randomized trial evidence to support or reject benefit or harm. Adverse effects from large doses of glucocorticoids are obvious, such as increased risks of secondary infection (Lionakis and Kontoyiannia, 2003). In the trials included in this review, we noticed that methylprednisolone was widely used for SARS in China, and the more severe the patients' conditions, the larger the dosage of glucocorticoids was used. However, the trials did not report long-term adverse effects from the use of glucocorticoids. Based on our personal contact with doctors who treated SARS patients in China and on information from the Internet (Xu, 2003), we have been informed that 20\%-40\% of SARS affected health professionals in Beijing had femoral head necrosis at discharge from the hospital. Early reports of case series in Guangzhou claimed that Chinese medicine combined with conventional drugs could reduce the dosage of corticosteroids (Lin et al., 2003). Our metaanalyses do not confirm this claim. However, findings from two trials show a benefit of the combined therapy in reducing the risk of secondary fungal infections, which may be related to the use of high doses of steroids. The mechanism of this benefit is not clear.

We also lack evidence from randomized trials that any of the conventional drugs, such as ribavirin or interferon (Loutfy et al., 2003), are effective. We have been unable to identify trials that compare either herbal medicines or conventional drugs to placebo for SARS patients. We only were able to identify one case series using herbal medicines alone for treatment of 16 SARS patients (Tong et al., 2003). In preparation for new outbreaks, investigators ought to develop international protocols for further well-designed clinical trials, which can be ready when new cases appear.

New treatment options are still needed, especially for an emerging disease such as SARS. Apart from this review on herbs, an in vitro study showed that glycyrrhizin (extract from liquorice root) may inhibit replication of the SARSassociated virus (Cinatl et al., 2003). Compared to the global case fatality rate of $11 \%(916 / 8422)$ by August 7, 2003, the fatality rates for Mainland China, Hong Kong, and Taiwan are $7 \%$ (349/5327), 17\% (300/1755), and 27\% (180/665), respectively (World Health Organization, 2003b). We do not know if these figures represent a potential benefit from the broad incorporation of herbal medicines into conventional treatment in Mainland China, or the lower case fatality rates reflect a cohort of healthier patients or the effect of different methods of fatality calculations in different regions (World Health Organization, 2003a).

\section{ACKNOWLEDGMENTS}

We thank Heather MacIntosh, Ph.D., and Heather Dubnick, Ph.D., for useful comments on our draft of the manuscript. We are grateful to Yunxia Liu, M.D., for assistance with searching for studies. Jianping Liu is supported by the Effective Health Care Alliance Programme (EHCAP) from the Department for International Development (DFID), UK. Eric Manheimer is supported by Grant Number 1 R24 AT001293-01 from the National Center for Complementary and Alternative Medicine (NCCAM), USA.

The authors have no affiliations with or involvement in any organization or entity with a direct financial interest in the subject matter of the review. The contents of the review are solely the responsibility of the authors and do not necessarily represent the official views of the authors' institutions.

J. Liu conceived, designed, drafted the review, and conducted the literature search, study selection, data extraction, analyses, and interpretation. E. Manheimer developed the search strategy, performed electronic searches, provided methodological perspectives, and revised the review. Y. Shi conducted the literature search, study selection, and data extraction. C. Gluud provided methodological perspectives and revised the review. All authors contributed to the writing of the review. J. Liu is a guarantor of the paper.

\section{REFERENCES}

Anonymous. Applying integrative Chinese and western medicine in fighting SARS [editorial]. Chin J Integr Med 2003;9:162-168. Bian YJ, Qi WS, Song QQ, Li GW, Fu YL, Tang XD, Jiang ZY, 
Wang YH. Evaluation on effect of integrative medical treatment on quality of life of rehabilitation stage in 85 patients with SARS. Chin J Integr Trad West Med 2003;23:658-660.

Chan K. Progress in traditional Chinese medicine. Trends Pharmacol Sci 1995;16:182-187.

Cinatl J, Morgenstern B, Bauer G, Chandra P, Rabenau H, Doerr HW. Glycyrrhizin, an active component of liquorice roots, and replication of SARS-associated coronavirus. Lancet 2003;361: 2045-2046.

Clarke M, Oxman AD, eds. Assessment of study quality. Cochrane Reviewers' Handbook 4.2.0 [updated March 2003]. In: The Cochrane Library, Issue 2, 2003. Oxford: Update Software.

Dai Y, Zhang D, Zhang R, Xue YX. Clinical report of QKL tablet for treatment and prevention of 515 SARS related cases (unpublished data). Online document at: www.enwei.com.cn/medicine/dsptext.asp? $1 \mathrm{mdm}=010002 \&$ file $=20038260100020200$. htm Accessed December 5, 2003.

Donnelly CA, Ghanl AC, Leung GM, Hedley AJ, Fraser C, Riley S, Abu-Raddad LJ, Ho LM, Thach TQ, Chau P, Chan KP, Lam TH, Tse LY, Tsang T, Liu SH, Kong JH, Lau EM, Ferguson NM, Anderson RM. Epidemiological determinants of spread of causal agent of severe acute respiratory syndrome in Hong Kong. Lancet 2003;361:1761-1766.

Duan BF. Summary of audio-vision symposium on preventing and treating SARS by integrative medicine between Taiwan and the mainland. Chin J Integr Trad West Med 2003;23:639-640.

Egger M, Davey Smith G, Schneider M, Minder C. Bias in metaanalysis detected by a simple graphical test. BMJ 1997;315: 629-634.

He XW, Hou YP, Zhang YL, Zhou YZ, Zhang T, Yuan Y, Li HM. Analysis on treatment of severe acute respiratory syndrome by integrated traditional Chinese and western medicine. Chin J Integr Trad West Med Intens Crit Care 2003;10:271-274.

Higgins JPT, Thompson SG, Deeks JJ, Altman DG. Measuring inconsistency in meta-analyses. BMJ 2003;327:557-560.

Jiao Q, Wang B, Zhang RL, Wang BG, Feng LM, Wang HJ, Luo YL, Yan X, Shen HQ, Ma YM, Xiong Y, Chen WH, Ma D, Cheng C, Zhou W. Clinical controlled study of integrative Chinese and western medicine in treating 49 cases of SARS. Chin J Integr Med 2003;9:175-180.

Kang J, Chen HW, Liu ZY. Clinical observation of 43 cases of infectious atypical pneumonia treated by integrated Chinese and western medicines. Shanxi J Trad Chin Med 2003;19:34-35.

Kjaergard LL, Villumsen J, Gluud C. Reported methodological quality and discrepancies between large and small randomized trials in meta-analyses. Ann Intern Med 2001;135:982-989.

Kunz R, Vist G, Oxman AD. Randomisation to protect against selection bias in healthcare trials (Cochrane Methodology Review). In: The Cochrane Library, Issue 4, 2003. Chichester, UK: John Wiley \& Sons, Ltd.

Lei CL, Wang J, Chen YQ. Clinical therapeutic observation on Qiankunning for treatment of severe acute respiratory syndrome. Online document at www.enwei.com.cn/medicine/dsptext.asp? $1 \mathrm{mdm}=010002 \&$ file $=20036100100020180 . \mathrm{htm}$ Accessed December 12, 2003.

Li H, Hua JB, Wang WD, Zou JP, Li GX, Ni Q, Liu XM, Zhao $\mathrm{H}, \mathrm{Lu}$ JX, Li N, Cui BN. Clinical observation of 40 cases of SARS in the restoration stage treated by an integrated therapy of TCM and western medicine. J Beijing Univ Trad Chin Med 2003a;26:74-76.
Li N, Zhai XH, Gao L, Xia H. Clinical study on Chinese medicine Qiankunning for treatment of infectious atypical pneumonia. Drug Eval 2003b:24-27.

Li XH, Zhang K, Hu JH, Yang Y, Liang LC. Clinical therapeutic observation of severe acute respiratory syndrome (SARS) treated by integrated Chinese and western medicine. Chin J Trad Chin Med Pharm 2003c;18:326-328.

Li XW, Jiang RM, Guo JZ. Glucocorticoid in the treatment of severe acute respiratory syndrome patients: A preliminary report. Chin J Internal Med 2003d;42:378-381.

Li ZJ, Bao FH, Li Q, Wang BS, Li YP, Wang LD. Clinical study on treatment of severe acute respiratory syndrome with integrated Chinese and western medicine. Chin J Integr Trad West Med Intens Crit Care 2003e;10:214-216.

Lin L, Han Y, Yang ZM, Liu WS, Zhang MZ, Tang GH, Xu YJ. Clinical observation of 103 patients of severe acute respiratory syndrome treated by integrative traditional Chinese and Western medicine. Chin J Integr Trad West Med 2003;23:409-413.

Lionakis MS, Kontoyiannia DP. Glucocorticoids and invasive fungal infections. Lancet 2003;362:1828-1838.

Loutfy MR, Blatt LM, Siminovitch KA, Ward S, Wolff B, Lho H, Pham DH, Deif H, LaMere EA, Chang M, Kain KC, Farcas GA, Ferguson P, Latchford M, Levy G, Dennis JW, Lai EK, Fish EN. Interferon alfacon-1 plus corticosteroids in severe acute respiratory syndrome: A preliminary study. JAMA 2003;290: 3222-3228.

Ma XL. Joining hands fighting SARS by Chinese medicine and western medicine-Interview by Chen Ke-ji academician of the Chinese Academy of Science [newspaper article]. Science Times 2003; May 21; 4th edition.

Mara MA, Jones SJ, Astell CR, Holt RA, et al. The genome sequence of the SARS-associated coronavirus. Science 2003;300:1399-1404.

Moher D, Pham B, Jones A, Cook DJ, Jadad AR, Moher M, et al. Does quality of reports of randomized trials affect estimates of intervention efficacy reported in meta-analyses. Lancet 1998;352:609-613.

Oba Y. The use of corticosteroids in SARS. N Engl J Med 2003;348:2034-2035.

Peiris JS, Lai ST, Poon LL, Guan Y, Yam LY, Lim W, Nicholls J, Yee WK, Yan WW, Cheung MT, Cheng VC, Chan KH, Tsang DN, Yung RW, Ng TK, Yuen KY; SARS study group. Coronavirus as a possible cause of severe acute respiratory syndrome. Lancet 2003;361:1319-1325.

Rota PA, Oberste MS, Monroe SS, et al. Characterization of a novel coronavirus associated with severe acute respiratory syndrome. Science 2003;300:1394-1399.

Schulz KF, Chalmers I, Hayes R, Altman D. Empirical evidence of bias. JAMA 1995;273:408-412.

State Administration of TCM of China. Technical protocol of traditional Chinese medicine for prevention and treatment of atypical pneumonia (SARS). Online document at: www.satcm. gov.cn/lanmu/yizheng/feidian_jishu.htm (Accessed December 17, 2003).

Sun ZJ, Li YM, Ji JL, Bi GQ, Mu Y, Chen X, Liu Y. Observation on therapeutic effects of traditional Chinese medicine in 26 patients with severe acute respiratory syndrome. Chin J Integr Trad West Med Intens Crit Care 2003;10:217-219.

Tong XL, Li AG, Zhang ZY, Duan J, Chen XG, Hua CJ, Zhao D, Xu Y, Shi XP, Li P, Tian X, Lin F, Cao YT, Lu J, Chang M, 
Wang YT. Clinical observation of 16 cases of infectious atypical pneumonia (SARS) treated by traditional Chinese medicines. J Trad Chin Med 2003;44:506-511.

Vickers A, Goyal N, Harland R, Rees R. Do certain countries produce only positive results? A systematic review of controlled trials. Control Clin Trials 1998;19:159-166.

Wang HJ. Fatal aspergillosis in a patient with SARS who was treated with corticosteroids. N Engl J Med 2003;349:507-508.

Wang RB, Liu JM, Jiang YY, Wu YZ, Xu DZ. Treatment of 11 patients with SARS by traditional Chinese medicine as main therapy. J Beijing Trad Chin Med 2003;22:8-9.

Wang ZM. Process of screening Chinese medicines for SARS. China News on Traditional Chinese Medicine. June 18, 2003. Online document at: www.cntcm.com.cn Accessed December 15, 2003.

Wenzel RP, Edmond MB. Managing SARS amidst uncertainty. N Engl J Med 2003;348:1947-1948.

Wong GWK, Hui DSC. Severe acute respiratory syndrome (SARS): Epidemiology, diagnosis and management. Thorax 2003;58:558-560.

World Health Organization. Consensus document on the epidemiology of severe acute respiratory syndrome (SARS). Online document at: www.WHO/CDS/CSR/GAR/2003.11. Accessed January 31, 2004.

World Health Organization. Severe acute respiratory syndrome (SARS). Online document at: www.who.int/csr/sars/ Accessed August 16, 2003b.

World Health Organization. Summary table of SARS cases by country, 1 November 2002-7 August 2003. Online document at: www.who.int/csr/sars/country/en/country2003_08_15.pdf Accessed December 8, 2003a.

$\mathrm{Xu} \mathrm{L}$. Integrated Chinese and western medicine for treating ischemic femur head necrosis. Online document at: www.ggt. com.cn/ Accessed December 8, 2003.
Zhang RL, Jiao Q, Wang BG, Feng LM, Wang B, Wang HJ, Luo YL, Yan X, Shen HQ, Ma YM, Xiong Y, Chen WH, Ma D, Cheng C, Zhou W. Controlled clinical study on 49 patients of SARS treated by integrative Chinese and western medicine. Chin J Integr Trad West Med 2003;23:654-657.

Zhang SN. Report of integrated Chinese and western medicine for treatment of SARS patients with pulmonary fibrosis and analysis of their clinical characteristics. Chin Gen Prac 2003a; 6:576-577.

Zhang XM, Zhang YL, Yang ZF, Jin YW, Tan XH, Zhang Y, Feng GL, Ma YM, Yang YQ, Wang MY, He YH, Zhang Y, Liu XS, Wang YL, Jin ZA, Lin Q, Liu WN. Clinical therapeutic observation of Fei Dian No. 1, 2, 3 formulations of herbs for treatment of SARS. Chin J Trad Chin Med Pharm 2003b;18: 323-325.

Zhao CH, Li XH, Zhang K, Jin RH, Gou CY, Hu ZJ, Ye J, Yang Y, Guo XH, Liang LC, Hu JH, Li XM, Wu JS. Randomized control study of integrated traditional Chinese and western medicine in treatment of 77 patients with severe acute respiratory syndrome. Chin J Integr Trad West Med Intens Crit Care 2003;10:197-200.

Address reprint requests to: Jianping Liu, M.D., Ph.D. International Health Research Group Liverpool School of Tropical Medicine Pembroke Place Liverpool L3 5QA United Kingdom

E-mail: jpliu@liv.ac.uk 